\title{
Minimally-Invasive versus Conventional Repair of Spondylolysis in Athletes: A Review of Outcomes and Return to Play
}

\author{
John Paul G. Kolcun, Lee Onn Chieng, Karthik Madhavan, Michael Y. Wang \\ Department of Neurological Surgery and The Miami Project to Cure Paralysis, University of Miami Miller School of Medicine, Miami, FL, USA
}

Spondylolysis from pars fracture is a common injury among young athletes, which can limit activity and cause chronic back pain. While current literature has examined the relative benefits of surgical and conservative management of these injuries, no study has yet compared outcomes between conventional direct repair of pars defects and modern minimally invasive procedures. The goals of surgery are pain resolution, return to play at previous levels of activity, and a shorter course of recovery. In this review, the authors have attempted to quantify any differences in outcome between patients treated with conventional or minimally invasive techniques. A literature search was performed of the PubMed database for relevant articles, excluding articles describing conservative management, traumatic injury, or high-grade spondylolisthesis. Articles included for review involved young athletes treated for symptomatic spondylolysis with either conventional or minimally invasive surgery. Two independent reviewers conducted the literature search and judged articles for inclusion. All studies were classified according to the North American Spine Society standards. Of the 116 results of our initial search, 16 articles were included with a total of 150 patients. Due to a paucity of operative details in older studies and inconsistencies in both clinical methods and reporting among most articles, little quantitative analysis was possible. However, patients in the minimally invasive group did have significantly higher rates of pain resolution $(p<0.001)$. Short recovery times were also noted in this group. Both groups experienced low complication rates, and the majority of patients returned to previous levels of activity. Surgical repair of spondylolysis in young athletes is a safe and practical therapy. Current literature suggests that while conventional repair remains effective, minimally invasive procedures better clinical outcomes. We await further data to conduct a more thorough quantitative analysis of these techniques.

Keywords: Pars; Spondylolysis; Minimally-invasive; MIS; Return to play

\section{Introduction}

Spondylolysis-a fracture of the pars interarticularis-is a common injury in young patients, and is often associated with spondylolisthesis. Typically, the rostral vertebral body gradually translates over the inferior body with minimal resistance from the posterior column. In younger patients, especially athletes, it is seen at the L5 level and is typically bilateral [1].

Historically, the incidence of spondylolysis has been reported as $6 \%$ in the general population [2], although newer studies utilizing computed tomography (CT) tech-

Received Sep 6, 2016; Revised Dec 19, 2016; Accepted Feb 16, 2017

Corresponding author: Lee Onn Chieng

Department of Neurological Surgery and The Miami Project to Cure Paralysis, University of Miami Miller School of Medicine, 1600 NW 10th Ave \#1140, Miami, FL 33136, Miami, FL, USA 33136-1015

Tel: +305-243-694, Fax: +305-243-3337, E-mail: cxl383@med.miami.edu 
nology have reported higher rates, as much as $11.5 \%$ [3] In young athletes, pars injuries occur with a much greater incidence, reported at anywhere from $23 \%-63 \%[4,5]$. Athletes at greatest risk engage in high-impact sports or activities that involve repetitive hyperextension, flexion, and rotation. There is some evidence for a hereditary predisposition to spondylolysis, such as a tendency for thin, more readily fractured vertebral bone, or an isolated weakness or thinning of the pars itself [6,7]. These fractures are also observed twice as frequently in men compared to women $[2,5,8]$.

Surgical repair of symptomatic spondylolysis is classically indicated after 6 months of failed conservative management, with persistent pain and non-union at 9-12 months $[9,10]$. Surgical decompression and fusion may also be indicated in symptomatic cases with neurologic deficit or radiculopathy.

While previous literature has compared the conservative and surgical management of spondylolysis [11], no study to date has analyzed differences in conventional direct repair (CDR) and minimally invasive surgery (MIS) techniques. This study will seek to compare outcomes between these approaches; in particular, the impact of MIS repair on return to play for athletes otherwise limited in their activity due to symptomatic fractures.

\section{Materials and Methods}

\section{Study selection}

With strict adherence to preferred reporting items for systematic reviews and meta-analyses (PRISMA) guidelines, a literature search was conducted of the PubMed database for articles relating to surgical repair of fractures to the pars interarticularis in athletes. Keywords included "pars interarticularis fracture" or "pars repair" or "spondylolysis repair," alone and in combination with phrases such as "athletes," "minimally invasive" or "MIS," and "direct repair."

Results were limited to English language literature and human subjects. Case reports and case series detailing surgical intervention for symptomatic spondylosis in athletes were included. Studies describing conservative management, treatment of injuries due to trauma, and patients with high-grade spondylolisthesis (greater than Meyerding Grade I) were excluded. Two reviewers performed the database search and reviewed each article for inclusion/ exclusion. The quality of evidence for each article was determined according to the standards of the North American Spine Society [12]. The last search was performed in April 2016.

Table 1. Studies included

\begin{tabular}{llll}
\hline Study & Technique & Type of study & Level of evidence \\
\hline Noggle et al., 2008 [14] & MIS & Case series & Level III \\
\hline Gillis et al., 2015 [13] & MIS & Case series & Level III \\
\hline Zhu et al., 2015 [20] & MIS & Case series & Level III \\
\hline Takata et al., 2014 [21] & MIS & Case series & Level III \\
\hline Sairyo et al., 2003 [29] & MIS & Case series & Level III \\
\hline Widi et al., 2013 [19] & MIS & Case series & Level III \\
\hline Brennan et al., 2008 [22] & MIS & Case report & Level III \\
\hline Mohi Eldin, 2012 [23] & MIS & Case report & Level III \\
\hline Reitman et al., 2002 [17] & Case series & Level III \\
\hline Nozawa et al., 2003 [15] & CDR & Case series & Level III \\
\hline Rajasekaran et al., 2011 [16] & CDR & Case series & Level III \\
\hline Snyde et al., 2014 [27] & CDR & Retrospective & Level III \\
\hline Lundin et al., 2003 [25] & CDR & Retrospective & Level III \\
\hline Ranawat et al., 2002 [26] & CDR & Retrospective & Level III \\
\hline Gillet et al., 1999 [24] & CDR & Retrospective & Level III \\
\hline Menga et al., 2014 [28] & CDR & Prospective & Level III \\
\hline
\end{tabular}

MIS, minimally invasive surgery; CDR, conventional direct repair. 
Table 2. Overall patient demographics

\begin{tabular}{lccc} 
Cohorts & No. of patients & Sex ratio (male:female, reported) & Mean patients age (yr) \\
Minimally invasive surgery & 46 & $26: 10$ & 32.9 \\
Conventional direct repair & 104 & $43: 32$ & 19.7 \\
\hline Total & 150 & $69: 42$ & 23.1 \\
\hline
\end{tabular}

\section{Data extraction and analysis}

Studies were first separated into MIS or CDR technique groups. Each study was analyzed for patient population, methods, outcomes, and complications. Various clinical metrics employed by different studies and other criteria were compared to assess differences in outcomes between MIS or CDR interventions.

\section{Results}

\section{Search procedure}

Our initial PubMed search yielded 143 results. After screening, 16 articles were included in this study, comprising 9 case series [13-21], 2 case reports [22,23], 4 retrospective studies [24-27], and 1 prospective study [28], with a total of 150 patients (Tables 1,2 ). 8 of these articles describe MIS therapy in 46 patients [13,14,18-23]. The remaining 8 articles describe CDR techniques in 104 patients [15-17,24-28] (Figs. 1, 2).

\section{Baseline characteristics}

1) MIS

Of the 46 patients treated with MIS techniques, $72 \%$ were male (of 36 reported) and the average age was 32.9 years. Athletes in this group participated in professional and college football, professional hockey, and high school sports including track and volleyball (Table 3 ).

\section{2) $\mathrm{CDR}$}

Of the 104 patients treated with CDR techniques, 57\% were male (of 75 reported) and the average age was 23.1 years. Athletes in this group participated in college gymnastics, baseball, and soccer, professional cricket, and amateur running, swimming, and golf. This group also included manual laborers, such as butchers, bricklayers, and fishmongers (Table 4).
143 Records identified through PubMed database search

16 Records screened

- No duplicates

.127 Records excluded with reason:

1) Editorial, commentary, review, technical note

2) Non-athletic population

3) Non-surgical therapy

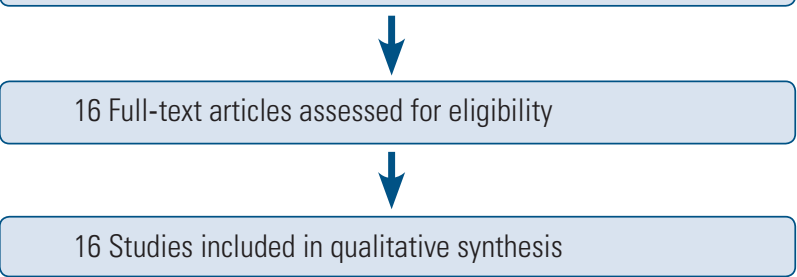

Fig. 1. Search procedure.

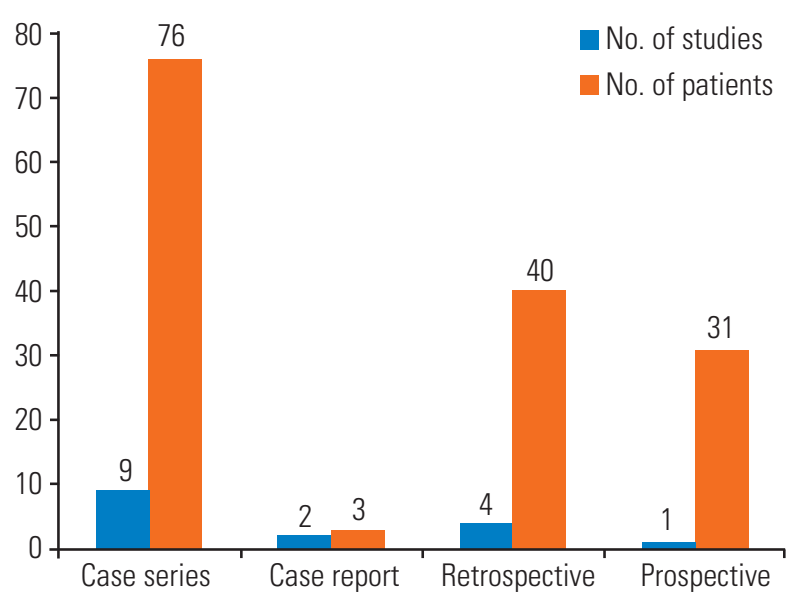

Fig. 2. Studies included.

\section{Presenting symptoms \& radiological findings}

1) MIS

The majority of patients presented with back pain. Other symptoms included leg pain and radiculopathy. Most patients had no spondylolisthesis, and those who did were all Meyerding Grade I ( $\mathrm{n}=13,28 \%)$. Vertebral level was reported in 47 injuries. While the majority of fractures were 
Table 3. Demographics, minimally invasive surgery studies

\begin{tabular}{lccc} 
Study & No. of patients & Sex ratio (male:female) & \multicolumn{2}{c}{ Mean patients age (yr) } \\
\hline Brennan et al., 2008 [22] & 1 & $1: 0$ & 17 \\
\hline Noggle et al., 2008 [14] & 5 & $4: 1$ & 15.8 \\
\hline Gillis et al., 2015 [13] & 7 & NA & NA \\
Zhu et al., 2015 [20] & 11 & $7: 4$ & 28.4 \\
\hline Mohi Eldin, 2012 [23] & 2 & $2: 0$ & 27 \\
\hline Takata et al., 2014 [21] & 10 & $8: 2$ & 33.2 \\
\hline Sairyo et al., 2003 [29] & 7 & $4: 3$ & 60.9 \\
Widi et al., 2013 [19] & 3 & $\mathrm{NA}$ & 20.7 \\
\hline
\end{tabular}

NA, not applicable.

Table 4. Demographics, conventional direct repair studies

\begin{tabular}{lccc} 
Study & No. of patients & Sex ratio (male:female) & Mean patients age (yr) \\
\hline Snyder et al., 2014 [27] & 16 & NA & 16 \\
Lundin et al., 2003 [25] & 5 & $1: 4$ & 16.2 \\
\hline Rajasekaran et al., 2011 [16] & 9 & $6: 3$ & 24 \\
\hline Ranawat, 2003 [26] & 9 & NA & 21.7 \\
\hline Menga et al., 2014 [28] & 31 & $14: 17$ & 16 \\
\hline Reitman et al., 2002 [17] & 4 & $14: 6$ & 17.8 \\
\hline Nozawa et al., 2003 [15] & 20 & $8: 2$ & 23.7 \\
\hline Gillet et al., 1999 [24] & 10 & & 26 \\
\hline
\end{tabular}

NA, not applicable.

Table 5. Overall clinical findings

\begin{tabular}{lcc} 
Presenting symptoms & Vertebral level & Side of injury \\
Minimally invasive surgery & & Unilateral-5 \\
Back pain, leg pain, radiculopathy & $L 3-2$ & Bilateral-41 \\
& $L 5-6$ & Unilateral-13 \\
Conventional direct repair & & Bilateral-57 \\
\hline Back pain, leg pain & $L 3-4$ & L4-9 \\
\end{tabular}

at the L5 level $(n=39,83 \%)$, injuries were also treated at L4 $(n=6,13 \%)$ and L3 $(n=2,9 \%)$. Most injuries were bilateral $(\mathrm{n}=41,89 \%)$ (Tables 5,6$)$.

\section{2) $C D R$}

Most patients presented with back pain. Other symptoms included leg or thigh pain, radiculopathy, and difficulty walking. The vast majority of patients had no spondylolis- thesis, and those who did were all Meyerding Grade I ( $\mathrm{n}=6$, $5.8 \%)$. Vertebral level was reported in 83 injuries. While the majority of fractures were at the L5 level $(n=69,83 \%)$, injuries were also treated at L4 $(n=9,11 \%), \mathrm{L} 3(n=4,5 \%)$, and L6 $(n=1,1.2 \%)$. Most injuries were bilateral $(n=52$, 80\%) (Table 7). 
Table 6. Clinical findings, minimally invasive surgery studies

\begin{tabular}{|c|c|c|c|c|}
\hline Study & Presenting symptoms & Vertebral level & Side of injury & Spondylolisthesis \\
\hline Brennan et al., 2008 [22] & Pain & L5 & Bilateral & NA \\
\hline Noggle et al., 2008 [14] & Pain & L5-5 & Bilateral-5 & NA \\
\hline Gillis et al., 2015 [13] & Back pain, leg complaints & $\begin{array}{l}\text { L3-2 } \\
\text { L5-5 }\end{array}$ & Bilateral-7 & NA \\
\hline Zhu et al., 2015 [20] & Back pain & $\begin{array}{l}\text { L4-2 } \\
\text { L5-9 }\end{array}$ & Bilateral-11 & Meyerding I-1 patients \\
\hline Mohi Eldin, 2012 [23] & Back pain, leg pain & $\begin{array}{l}\text { L4-1 } \\
\text { L5-1 }\end{array}$ & Bilateral-2 & Meyerding $\mid-1$ patients \\
\hline Takata et al., 2014 [21] & Back pain, leg pain & L5-10 & Bilateral-10 & Meyerding I-8 patients \\
\hline Sairyo et al., 2003 [29] & Low back pain, radiculopathy & $\begin{array}{l}\mathrm{L} 4+\mathrm{L} 5-1 \\
\mathrm{~L} 5-6\end{array}$ & $\begin{array}{l}\text { Unilateral-5 } \\
\text { Bilateral-2 }\end{array}$ & Meyerding I-3 patients \\
\hline Widi et al., 2013 [19] & Back pain & $\begin{array}{l}\text { L4-2 } \\
\text { L5-1 }\end{array}$ & Bilateral-3 & NA \\
\hline
\end{tabular}

NA, not applicable.

Table 7. Clinical findings, conventional direct repair studies

\begin{tabular}{|c|c|c|c|c|}
\hline Study & Presenting symptoms & Vertebral level & Side of injury & Spondylolisthesis \\
\hline Snyder et al., 2014 [27] & Back pain, Radiculopathy & $\begin{array}{l}\text { L3-2 } \\
\text { L4-3 } \\
\text { L5-11 }\end{array}$ & $\begin{array}{l}\text { Unilateral-3 } \\
\text { Bilateral-13 }\end{array}$ & NA \\
\hline Lundin et al., 2003 [25] & Back pain, Thigh pain & L5-5 & Bilateral-5 & Meyerding I-2 patients \\
\hline Rajasekaran et al., 2011 [16] & Low back pain & NA & $\begin{array}{l}\text { Unilateral-2 } \\
\text { Bilateral-7 }\end{array}$ & Meyerding $1-2$ patients \\
\hline Ranawat et al., 2003 [26] & Back pain & NA & $\begin{array}{l}\text { Unilateral-4 } \\
\text { Bilateral-5 }\end{array}$ & NA \\
\hline Menga et al., 2014 [28] & Low back pain & $\begin{array}{l}\text { L3-2 } \\
\text { L4-3 } \\
\text { L5-25 } \\
\text { L6-1 }\end{array}$ & $\begin{array}{l}\text { Unilateral-4 } \\
\text { Bilateral-27 }\end{array}$ & Meyerding I-2 patients \\
\hline Reitman et al., 2002 [17] & Back pain, leg pain & L5-4 & NA & NA \\
\hline Nozawa et al., 2003 [15] & Back pain, leg pain, difficulty walking & $\begin{array}{l}\text { L4-1 } \\
\text { L5-18 } \\
\text { L4+L5-1 }\end{array}$ & NA & NA \\
\hline Gillet et al., 1999 [24] & Low back pain, thigh pain & $\begin{array}{l}\text { L4-1 } \\
\text { L5-9 }\end{array}$ & NA & NA \\
\hline
\end{tabular}

NA, not applicable.

\section{Surgical techniques}

The majority of patients in both groups were treated by Buck's procedure or MIS/endoscopic modifications of Buck's procedure. In the CDR group, approximately $71 \%$ of patients were treated with Buck's procedure. Other techniques were also listed in Tables 8 and 9.

\section{1) MIS}

Of the 8 studies, most employed a MIS modification of Buck's procedure $(n=5,62.5 \%)$. In a typical percutaneous adaptation of Buck's technique, the patient is positioned prone, and the target pars defect is localized by fluoroscopy. A needle is introduced to the adjacent lamina, and a guide-wire is next drilled through the injured pars with $\mathrm{X}$-ray guidance. The trajectory is sequentially dilated, 
Table 8. Technique, minimally invasive surgery studies

\begin{tabular}{|c|c|c|c|c|}
\hline Study & Surgical technique & $\begin{array}{l}\text { Operative time } \\
\text { (min, mean) }\end{array}$ & $\begin{array}{l}\text { Blood loss } \\
\text { (mL, mean) }\end{array}$ & Complications \\
\hline Brennan et al., 2008 [22] & Modified Buck's & NA & $<20$ & None \\
\hline Noggle et al., 2008 [14] & Pedicle screws, rods, laminar hooks & 116.4 & 37 & None \\
\hline Gillis et al., 2015 [13] & Dinesys cable system & 127 & $<50$ & Medial breech, Pseudoarthrosis \\
\hline Zhu et al., 2015 [20] & Modified Buck's & 147.6 & 54.9 & None \\
\hline Mohi Eldin, 2012 [23] & Modified Buck's & 125 & 50 & None \\
\hline Takata et al., 2014 [21] & Endoscopic modified Buck's & 277.7 & 278.7 & None \\
\hline Sairyo et al., 2003 [29] & Endoscopic Foley \& Smith & 184.3 & NA & None \\
\hline Widi et al., 2013 [19] & Modified Buck's & NA & NA & None \\
\hline
\end{tabular}

Table 9. Technique, conventional direct repair studies

\begin{tabular}{lcc} 
Study & Surgical technique & Complications \\
\hline Snyder et al., 2014 [27] & Buck's & Wound infection-2, Pseudarthrosis, Radiculopathy \\
\hline Lundin et al., 2003 [25] & Buck's & None \\
\hline Rajasekaran et al., 2011 [16] & Buck's & None \\
\hline Ranawat et al., $2002[26]$ & Buck's & Drill break \\
\hline Menga et al., 2014 [28] & Buck's & Wound infection, Screw fracture-2 \\
\hline Reitman et al., $2002[17]$ & Buck's & None \\
\hline Nozawa et al., 2003 [15] & Scott's & Wire break-2, Wire pull \\
\hline Gillet et al., 1999 [24] & Pedicle screws, V-shaped rod & None \\
\hline
\end{tabular}

and the defect tapped and drilled before introduction of the pars screw. Two studies employed endoscopic procedures, including modifications of Buck's procedure with pedicle screws and the Foley and Smith approach. The mean reported operative time was 176.5 minutes (range, 116.4-277.7 minutes). The mean reported blood loss was $112.4 \mathrm{~mL}$ (range, 20-278.7 mL). The mean reported hospital stay was 1.67 days (Table 8 ).

\section{2) $\mathrm{CDR}$}

The most common technique was Buck's procedure ( $\mathrm{n}=6$, $75 \%)$. Only Rajasekaran et al. reported operative time, with a mean of 58 minutes (range, 45-75 minutes). 2 studies reported blood loss: Lundin et al. reported a mean loss of $146 \mathrm{~mL}$ (ragne, 100-200 mL), and Rajasekaran et al. reported a mean loss of $98 \mathrm{~mL}$ (range, 50-140 mL). Only Lundin et al. reported postoperative hospital stay, with a mean length of 3.2 days (Table 9).

\section{Clinical outcomes}

1) MIS

Three studies employed the visual analogue scale (VAS) to assess pre- and postoperative symptoms: Gillis et al. reported a reduction of 3 and 1.5 points for back and leg pain respectively, Zhu et al. reported a decrease from $7.1 \pm 2.3$ to $1.8 \pm 0.4(p=0.01)$, and Takata et al. reported a mean decrease from 7.6 to 2.5 for back pain and 3.4 to 2.0 for leg pain. Takata et al. also utilized the Japanese Orthopedic Association (JOA) functional score, reporting a mean increase from 15.8 to 26.4. Gillis et al. used the short form survey (SF)-36 physical and mental components (PCS and MSC, respectively) to assess patients' subjective outcome, reporting improvements of 12.2 and 2.9 for the PCS and MCS, respectively. Mohi Eldin reported Oswestry disability index (ODI) reductions in both patients, by $53 \%$ and $55 \%$, respectively.

All patients had good clinical outcomes with resolution of pain. Our pooled analysis of patients' postoperative 


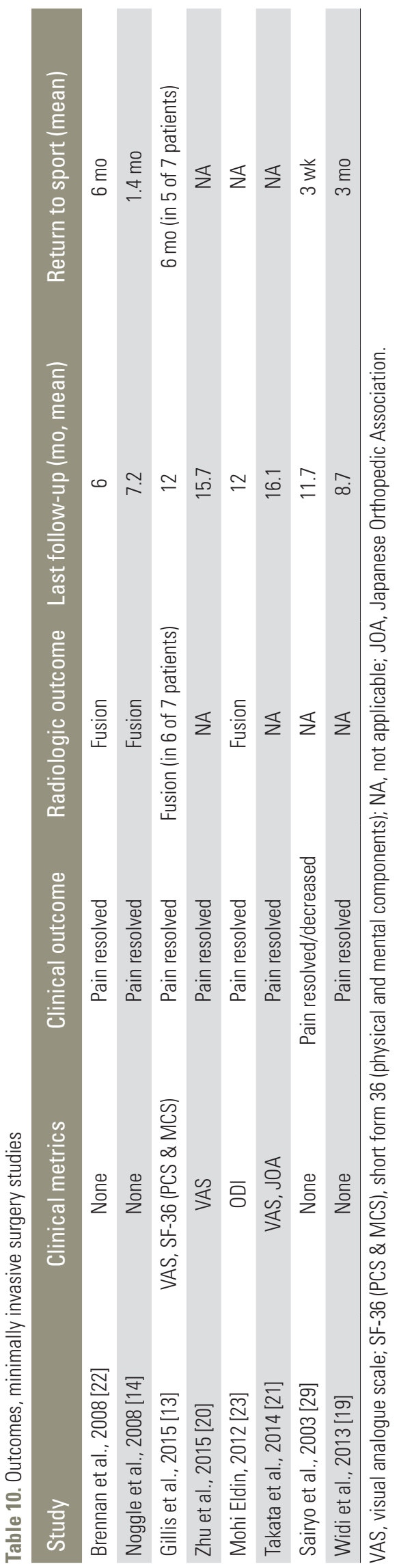

pain resolution found a significantly higher rate of complete resolution among patients treated with MIS techniques $(p=0.001$ ). Unfortunately, inconsistency in clinical metrics and reporting between studies precludes further quantitative outcomes analysis.

Five studies reported length of hospital stay, with a mean length of 1.67 days (range, 1-3 days). All athletes returned to their previous level of activity with the exception of two patients treated by Gillis et al. One patient underwent surgery for fusion at the same level as his pars repair 4 years postoperatively, at which time a broken Dynesys cable was noted. Another patient developed pseudoarthrosis with a recurrence of preoperative symptoms 18 months after surgery, after which CT scan demonstrated incomplete fusion across the pars. The average time for successful return to sport among athletes was 2.7 months (range, 0.75-6.0 months).

Four studies reported radiologic assessment of fusion. Fusion was achieved in all patients but one treated by Gillis et al. (described above). On average, patients were followed postoperatively for 12.7 months (range, 6-23 months) (Table 10).

\section{2) CDR}

Menga et al. employed the VAS to assess pre- and postoperative symptoms, reporting a decrease from a mean score of 7 preoperatively (range, 1-10) to 2 postoperative (range, $0-10$ ). The 25 athletes treated had a postoperative mean score of 1 (range, $0-4$ ). Nozawa et al. used the JOA functional score, reporting a mean preoperative score of $21.2 \pm 3.9$ (range, 13-26) and a mean postoperative score of 27.7 \pm 1.0 (range, 26-29). Finally, Gillet et al. used the Prolo Economic Status score to assess postoperative outcomes. Postoperatively, patients had an average economic score of 4.0 (2-5) and an average functional score of 4.0 (range, 2-5), with a combined average of 8.0 (range, 4-10). The majority of patients reported a resolution of pain $(\mathrm{n}=78,75 \%)$. Of the remaining patients, over half had some improvement ( $n=20,19 \%)$, while some had no postoperative change $(n=4,3.9 \%)$.

Only Lundin et al. reported postoperative length of hospital stay, with a mean stay of 3.2 days (range, 3-4 days). All patients returned to their previous level of activity but three: Rajasekaran et al. reported one patient with persistent back pain in whom MRI suggested disc degeneration. Gillet et al. reported two patients whose poor surgical outcome prevented return to previous activity. Three stud- 


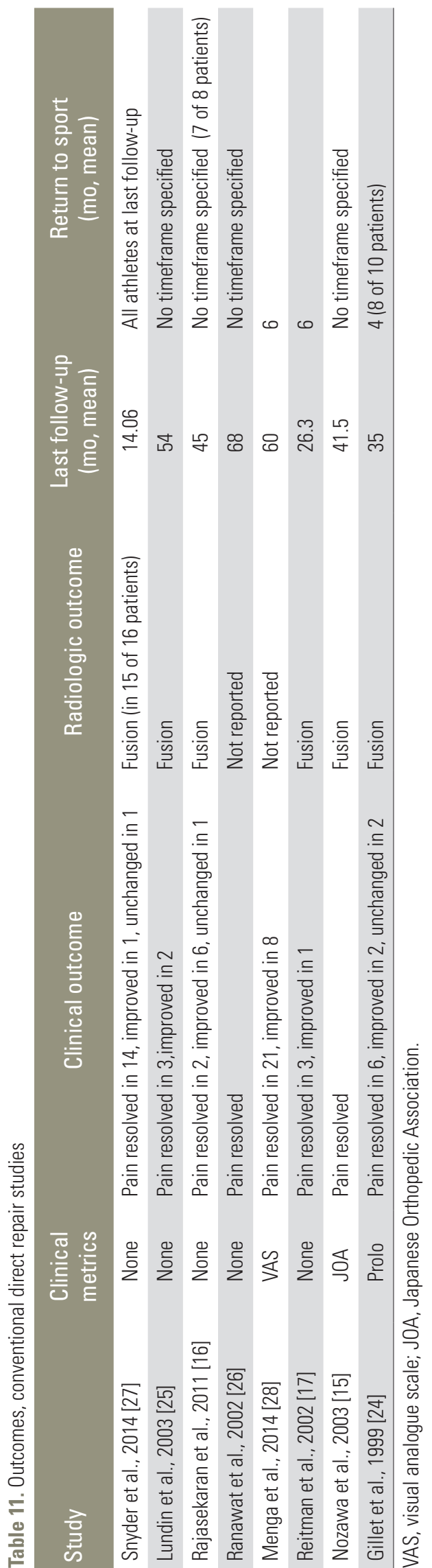

ies reported the length of time before patients returned to sport, with a mean of 5.6 months (range, 4-6 months).

Six studies reported postoperative radiographic outcomes. Of these, all patients had confirmed fusion except for one patient treated by Snyder et al. had two pars defects, one of which did not fuse successfully. On average, patients were followed postoperatively for 44.8 months (range, 9-135 months) (Table 11).

\section{Complications}

\section{1) MIS}

Only two complications were reported, both in patients treated by Gillis et al. As described above, one patient developed pseudoarthrosis and experienced a recurrence of symptoms at 18 months postoperatively. Another patient experienced postoperative radiculopathy due to a medial breech, requiring screw revision (Table 8).

\section{2) $\mathrm{CDR}$}

Eleven complications were reported. Snyder et al. reported two patients who developed postoperative superficial wound infections, which were treated with no effect on recovery. Two patients required revision surgery: one for pseudarthrosis and the other for radiculopathy, both of which developed postoperatively. Ranawat et al. reported one case of a perioperative drill break, which required removal during surgery. Menga et al. reported one patient with a postoperative superficial skin infection which was treated successfully without impact on recovery, and two patients with screw fractures: one was asymptomatic and found incidentally, the other was symptomatic (VAS=10). Finally, Nozawa et al. reported one patient in which a wire was displaced 2 weeks postoperatively and required repair with a pedicle screw, and two patients with asymptomatic postoperative wire breakage at 30 and 32 months respectively. As fusion had occurred by this point, neither patient required repair or revision (Table 9).

\section{Discussion}

In 1970, Buck [30] described a method of spondylolysis correction by which screws are placed directly through the fractured pars and ipsilateral lamina. The goal of this procedure was to repair the pars defect so as to prevent the development of spondylolisthesis, the treatment of which had a relatively low success rate. His technique remains popular, and has formed the basis of CDR approaches to 
pars defects. Today, growing interest in MIS neurosurgery has led to the development of MIS modifications of Buck's procedure for the internal fixation of pars defects.

Direct repair is not, however, the only strategy available to treat these injuries. Transforaminal endoscopic microdiscectomy was performed in a 31-year-old patient with foraminal stenosis and symptomatic pain radiating to his legs. This patient had minimal spondylolisthesis and stable flexion/extension X-ray images [31]. Postoperatively, the patient experienced a complete resolution of his symptomatic pain. This technique-as with the MIS techniques reviewed here-may be particularly applicable in patients who do not require fusion. Kakiuchi [32] has reported spondylolysis repair by fixation with pedicle screws and laminar hooks in 16 patients, 13 of whom had complete pain resolution, while the remaining 3 complain of only occasional postoperative back pain. These patients had an average age of 32 years (range, 12-60 years).

Of the patients included in this review, those undergoing MIS repair experienced significantly greater resolution of symptomatic pain. While disparities in reporting and metrics between various studies precludes a more rigorous statistical analysis, the MIS patient population in this study is more than 10 years older on average than the CDR population. This may reflect the general benefits of MIS surgery: less surgical stress (e.g., tissue destruction, blood loss), which allows expansion of the candidate population to older patients. We therefore argue for the application of MIS techniques in pars repair, as this approach offers greater treatment of symptoms in a wider range of patients.

The ultimate goal of pars repair-beyond resolution of pain-is the return to play of an injured athlete at preoperative levels. Current literature suggests a postoperative delay of anywhere from 6-12 months before a patient who has undergone pars repair can return to play $[10,11,33]$. The studies included in this review did not consistently report return to play. Many of those that did failed to specify the timeframe involved. However, 3 MIS studies did report return to play times of 1.4 months [14], 3 months [19], and even 3 weeks [18]. These outcomes may suggest that the trauma of surgery itself delays an athlete's return to play after pars repair, and that MIS techniques therefore afford the patient a more rapid return to previous activity levels.

This review does face limitations. The small number of patients involved prevents broad generalization of our conclusions. As mentioned, the studies included were rarely consistent in clinical metrics used or reported, preventing a thorough quantitative statistical analysis. These studies were predominately case series, and therefore the patients involved were not randomized, but selected for their various treatments with bias. In CDR, there were many complications that may not related to magnitude of surgery but related to hardware failure. This could reflect an artifact of the literature, as our report includes approximately twice as many CDR patients as MIS. There may also be some characteristic of the techniques or hardware employed by CDR/MIS techniques influencing hardware failure, but due to the disparity of variables reported by these studies we cannot conduct meaningful analysis.

\section{Conclusions}

The direct repair of spondylolysis is an effective therapy for athletes in whom conservative management has failed. As new MIS techniques are developed and reported, a growing body of evidence suggests that these approaches may offer patients higher resolution of symptomatic pain and a swifter recovery with return to play when compared to traditional CDR techniques. More numerous and thorough data are required to conduct a quantitative analysis and draw firm conclusions.

\section{Conflict of Interest}

No potential conflict of interest relevant to this article was reported.

\section{References}

1. Leone A, Cianfoni A, Cerase A, Magarelli N, Bonomo L. Lumbar spondylolysis: a review. Skeletal Radiol 2011;40:683-700.

2. Fredrickson BE, Baker D, McHolick WJ, Yuan HA, Lubicky JP. The natural history of spondylolysis and spondylolisthesis. J Bone Joint Surg Am 1984;66:699707.

3. Kalichman L, Kim DH, Li L, Guermazi A, Berkin V, Hunter DJ. Spondylolysis and spondylolisthesis: prevalence and association with low back pain in the adult community-based population. Spine (Phila $\mathrm{Pa}$ 1976) 2009;34:199-205.

4. Cavalier R, Herman MJ, Cheung EV, Pizzutillo PD. 
Spondylolysis and spondylolisthesis in children and adolescents: I. Diagnosis, natural history, and nonsurgical management. J Am Acad Orthop Surg 2006;14:417-24.

5. Foreman P, Griessenauer CJ, Watanabe K, et al. L5 spondylolysis/spondylolisthesis: a comprehensive review with an anatomic focus. Childs Nerv Syst 2013;29:209-16.

6. Albanese M, Pizzutillo PD. Family study of spondylolysis and spondylolisthesis. J Pediatr Orthop 1982;2:496-9.

7. Wynne-Davies R, Scott JH. Inheritance and spondylolisthesis: a radiographic family survey. J Bone Joint Surg Br 1979;61:301-5.

8. Belfi LM, Ortiz AO, Katz DS. Computed tomography evaluation of spondylolysis and spondylolisthesis in asymptomatic patients. Spine (Phila Pa 1976) 2006;31:E907-10.

9. d'Hemecourt PA, Zurakowski D, Kriemler S, Micheli LJ. Spondylolysis: returning the athlete to sports participation with brace treatment. Orthopedics 2002;25:653-7.

10. Radcliff KE, Kalantar SB, Reitman CA. Surgical management of spondylolysis and spondylolisthesis in athletes: indications and return to play. Curr Sports Med Rep 2009;8:35-40.

11. Bouras T, Korovessis P. Management of spondylolysis and low-grade spondylolisthesis in fine athletes: a comprehensive review. Eur J Orthop Surg Traumatol 2015;25 Suppl 1:S167-75.

12. North American Spine Society. Levels of Evidence for Primary Research Question [Internet]. Washington, DC: North American Spine Society; [cited 2017 Aug 20]. Available from: https://www.spine.org/Documents/ResearchClinicalCare/LevelsOfEvidence.pdf.

13. Gillis CC, Eichholz K, Thoman WJ, Fessler RG. A minimally invasive approach to defects of the pars interarticularis: restoring function in competitive athletes. Clin Neurol Neurosurg 2015;139:29-34.

14. Noggle JC, Sciubba DM, Samdani AF, Anderson DG, Betz RR, Asghar J. Minimally invasive direct repair of lumbar spondylolysis with a pedicle screw and hook construct. Neurosurg Focus 2008;25:E15.

15. Nozawa S, Shimizu K, Miyamoto K, Tanaka M. Repair of pars interarticularis defect by segmental wire fixation in young athletes with spondylolysis. Am J Sports Med 2003;31:359-64.
16. Rajasekaran S, Subbiah M, Shetty AP. Direct repair of lumbar spondylolysis by Buck's technique. Indian J Orthop 2011;45:136-40.

17. Reitman CA, Esses SI. Direct repair of spondylolytic defects in young competitive athletes. Spine J 2002;2:142-4.

18. Sairyo K, Sakai T, Yasui N. Minimally invasive technique for direct repair of pars interarticularis defects in adults using a percutaneous pedicle screw and hook-rod system. J Neurosurg Spine 2009;10:492-5.

19. Widi GA, Williams SK, Levi AD. Minimally invasive direct repair of bilateral lumbar spine pars defects in athletes. Case Rep Med 2013;2013:659078.

20. Zhu X, Wang J, Zhou Y, Zhang Z, Li C, Zheng W. Minimally invasive surgery for direct repair of lumbar spondylolysis by utilizing intraoperative navigation and microendoscopic techniques. Zhongguo Xiu Fu Chong Jian Wai Ke Za Zhi 2015;29:1244-8.

21. Takata Y, Sakai T, Tezuka F, Goda Y, Higashino K, Sairyo K. Clinical outcome of minimally invasive repair of pars defect using percutaneous pedicle screws and hook-rod system in adults with lumbar spondylolysis. Ann Orthop Rhematol 2014;2:1013.

22. Brennan RP, Smucker PY, Horn EM. Minimally invasive image-guided direct repair of bilateral L-5 pars interarticularis defects. Neurosurg Focus 2008;25:E13.

23. Mohi Eldin M. Minimal access direct spondylolysis repair using a pedicle screw-rod system: a case series. J Med Case Rep 2012;6:396.

24. Gillet P, Petit M. Direct repair of spondylolysis without spondylolisthesis, using a rod-screw construct and bone grafting of the pars defect. Spine (Phila Pa 1976) 1999;24:1252-6.

25. Lundin DA, Wiseman D, Ellenbogen RG, Shaffrey CI. Direct repair of the pars interarticularis for spondylolysis and spondylolisthesis. Pediatr Neurosurg 2003;39:195-200.

26. Ranawat VS, Dowell JK, Heywood-Waddington MB. Stress fractures of the lumbar pars interarticularis in athletes: a review based on long-term results of 18 professional cricketers. Injury 2003;34:915-9.

27. Snyder LA, Shufflebarger H, O'Brien MF, Thind H, Theodore N, Kakarla UK. Spondylolysis outcomes in adolescents after direct screw repair of the pars interarticularis. J Neurosurg Spine 2014;21:329-33.

28. Menga EN, Kebaish KM, Jain A, Carrino JA, Spon- 
seller PD. Clinical results and functional outcomes after direct intralaminar screw repair of spondylolysis. Spine (Phila Pa 1976) 2014;39:104-10.

29. Sairyo K, Katoh S, Sakamaki T, Komatsubara S, Yasui $\mathrm{N}$. A new endoscopic technique to decompress lumbar nerve roots affected by spondylolysis: technical note. J Neurosurg 2003;98(3 Suppl):290-3.

30. Buck JE. Direct repair of the defect in spondylolisthesis. Preliminary report. J Bone Joint Surg Br 1970;52:432-7.

31. Madhavan K, Chieng LO, Hofstetter CP, Wang MY.
Transforaminal endoscopic discectomy to relieve sciatica and delay fusion in a 31-year-old man with pars defects and low-grade spondylolisthesis. Neurosurg Focus 2016;40:E4.

32. Kakiuchi M. Repair of the defect in spondylolysis. Durable fixation with pedicle screws and laminar hooks. J Bone Joint Surg Am 1997;79:818-25.

33. Drazin D, Shirzadi A, Jeswani S, et al. Direct surgical repair of spondylolysis in athletes: indications, techniques, and outcomes. Neurosurg Focus 2011;31:E9. 